OPEN ACCESS

Edited by:

Michele Caraglia,

Università degli Studi della Campania

"Luigi Vanvitelli"Caserta, Italy

Reviewed by:

Marco Centanni,

Sapienza Università di Roma, Italy

Marialuisa Appetecchia,

Istituti Fisioterapici Ospitalieri

(IRCCS), Italy

*Correspondence: Kate Newbold

Kate.Newbold@icr.ac.uk

Specialty section: This article was submitted

to Cancer Endocrinology, a section of the journal

Frontiers in Endocrinology

Received: 26 July 2017 Accepted: 27 October 2017 Published: 20 November 2017

Citation:

Tumino D, Frasca F and Newbold $K$ (2017) Updates on the Management

of Advanced, Metastatic,

and Radioiodine Refractory

Differentiated Thyroid Cancer.

Front. Endocrinol. 8:312.

doi: 10.3389/fendo.2017.00312

\section{Updates on the Management of Advanced, Metastatic, and Radioiodine Refractory Differentiated Thyroid Cancer}

\author{
Dario Tumino ${ }^{1,2}$, Francesco Frasca ${ }^{2}$ and Kate Newbold ${ }^{1 *}$ \\ ${ }^{1}$ Clinical Oncology, Royal Marsden NHS Foundation Trust, London, United Kingdom, ${ }^{2}$ Endocrinology, Department of Clinical \\ and Experimental Medicine, University of Catania, Garibaldi-Nesima Medical Center, Catania, Italy
}

Differentiated thyroid cancer (DTC) accounts for 95\% of all thyroid cancers and is generally an indolent tumor, treated effectively with surgery, radioactive iodine, and thyroid-stimulating hormone suppressive therapy. However, $5-10 \%$ of patients have advanced disease, with aerodigestive tract invasion, distant metastases, or radioiodine refractory disease, with poor prognosis. This review focuses on the approaches for treating advanced DTC, including management of gross extra-thyroidal extension, recurrent loco-regional or distant metastatic disease, the role of external beam radiation therapy and systemic treatment. Locally ablative treatment modalities, including surgery, radiation therapy, and thermal ablation are evolving and can be used in selected patients. In recent years, new therapeutic agents with molecular targets have become available and two multi-kinase inhibitors, Sorafenib and Lenvatinib, have been licensed for iodine refractory DTC showing an advantage in terms of progression-free survival, although an impact on overall survival has not been proven yet. Management of advanced thyroid cancer can be challenging but a multidisciplinary approach can significantly improve outcomes for this patient population.

Keywords: thyroid cancer, radioiodine refractory, kinase inhibitors, redifferentiation, distant metastasis

\section{INTRODUCTION}

Thyroid cancer has a wide range of clinical behavior from an indolent tumor with low mortality in most cases to aggressive disease. Both papillary and follicular cancers arise from thyroid follicular epithelial cells and they are grouped together under the umbrella term differentiated thyroid cancer (DTC), accounting for $95 \%$ of cases. Surgery followed by radioactive iodine or observation effects a cure in the majority (1). Approximately $5 \%$ of patients with DTC will present with locally advanced disease $(2,3)$. Distant metastases will develop in $10 \%$ and it is the distant metastases that are the main cause of thyroid cancer-related deaths with overall mortality rates of $65 \%$ and $75 \%$ at 5 and 10 years, respectively (4). The American Thyroid Association (ATA) Guidelines classify DTC with gross extra-thyroidal extension (ETE), distant metastases, incomplete tumor resection, inappropriately high postoperative thyroglobulin $(\mathrm{Tg})$, involved lymph nodes greater than $3 \mathrm{~cm}$ and follicular cancer with extensive vascular invasion, as "high risk" for recurrence (5). About one-third of advanced DTC (A-DTC) have metastatic lesions with low avidity for iodine at the time of diagnosis (6). This can also occur during the progression of the disease, 
when the ability to concentrate radioiodine (RAI) is lost or the tumor progresses despite significant uptake of RAI. These three situations, together with a mixed picture of both RAI avid and non-avid disease, often 2-[(18)F] fluoro-2-deoxyglucose (FDG) avid, defines "radioiodine-refractory" DTC (RR-DTC) (7). Poorly differentiated thyroid carcinoma (PDTC) and anaplastic thyroid carcinoma (ATC) are rare, accounting for 3-5\% and $1 \%$ of all thyroid cancers, respectively, and are the most aggressive follicular cell-derived thyroid cancer. Poorly DTC and ATC generally do not take up RAI, may not secrete Tg or respond to thyroid-stimulating hormone (TSH) (8). Poorly DTC should be histologically distinguished from well-differentiated papillary and follicular cancers (5). Despite the low incidence, PDTC accounts for a disproportionate number of thyroid cancerrelated deaths because of its resistance to the most common therapeutic approaches. Medullary thyroid cancer (MTC) originates from the para-follicular C-cells of the thyroid accounts for $1-2 \%$ of thyroid cancer, but will not be discussed here. This review will describe the current treatment of locally A-DTC, metastatic DTC and RR-DTC (Figure 1).

\section{LOCALLY A-DTC}

Extensive ETE is rare, reported to occur in $4-8 \%$ of patients with DTC at the time of diagnosis $(3,9)$. These patients are classified as pT4 using the AJCC/UICC TNM system, defining T4a as a tumor of any size extending beyond the thyroid capsule to invade subcutaneous soft tissues, larynx, trachea, esophagus, or recurrent laryngeal nerve, and $\mathrm{T} 4 \mathrm{~b}$ as tumor invading prevertebral fascia or encasing the carotid artery or mediastinal vessels (10). Contrast enhanced CT, MRI, and endoscopy (to specifically assess endo-luminal involvement) are useful investigations to accurately assess extent of disease and avoid under-staging, thereby informing the correct management decisions (11). Surgery is the primary treatment modality of choice for A-DTC, to resect all gross disease while minimizing morbidity. A dedicated thyroid surgeon with a high-volume practice is critical to achieve this. A more conservative approach may be considered in patients with minimal visceral invasion, allowing "shave procedures" to remove macroscopic disease while accepting there will be residual microscopic disease, which may be managed with adjuvant RAI (12). In the event of transmural invasion of the esophagus, trachea or larynx a full thickness resection is recommended if possible. When the invasion is limited to the superficial layers, there is no consensus as to the extent of surgery, with some groups recommending an aggressive approach and others a more conservative approach with adjuvant therapy. For patients with distant metastases, although cure is unlikely to be achieved, there is still a role for surgery. Total thyroidectomy, if possible, allows subsequent treatment of metastatic disease with RAI. Palliative resection of bulky disease may reduce distressing symptoms such as airway compromise or hemorrhage.

\begin{tabular}{|c|c|}
\hline Surgery & - Procedure of choice for initial management of DTC \\
\hline $\begin{array}{l}\text { RAI } \\
\text { adjuvant treatment }\end{array}$ & $\begin{array}{l}\text { Including: } \\
\text { - Gross extrathyroid extension (T4) } \\
\text { - Distant metastases (M1) } \\
\text { - Follicular thyroid cancer with extensive vascular invasion ( }>4 \text { foci) } \\
\text { - Incomplete tumour resection } \\
\text { - A lymph node greater than } 3 \mathrm{~cm} \\
\text { - Inappropriately high postoperative thyroglobulin level }\end{array}$ \\
\hline TSH suppressive therapy & - TSH goal: $<0,1 \mathrm{mU} / \mathrm{L}$ \\
\hline $\begin{array}{l}\text { External Beam Radiation } \\
\text { Therapy (EBRT) }\end{array}$ & $\begin{array}{l}\text { - Consider in selected patients with aero-digestive tract invasion, where there is gross } \\
\text { residual disease (R2 resection) }\end{array}$ \\
\hline $\begin{array}{l}\text { Recurrent locoregional or } \\
\text { distant metastatic disease }\end{array}$ & $\begin{array}{l}\text { - Consider surgery or locally ablative interventions for locoregional or low volume } \\
\text { distant metastatic disease } \\
\text { - Observation for significant progression or symptoms }\end{array}$ \\
\hline Systemic treatment & $\begin{array}{l}\text { - RAI refractory DTC with significant clinical progression } \\
\text { - Symptomatic disease that cannot be managed with local treatment } \\
\text { - Disease near critical structures (not amenable to local treatment) likely to cause } \\
\text { imminent problems }\end{array}$ \\
\hline
\end{tabular}

FIGURE 1 | Treatment approach for a patient with advanced differentiated thyroid cancer. 
External beam radiotherapy (EBRT) may also palliate symptoms. A personalized approach should be applied to the patient and preferably discussed within a multi-disciplinary setting. RAI is recommended for ATA high risk patients after total thyroidectomy with the purpose of not only ablating normal remnant but also as an adjuvant treatment for residual microscopic disease (5). Subsequent therapy doses may be required if ablation does not result in complete response. EBRT may be considered adjuvantly in selected patients with aerodigestive tract invasion or where there is gross residual disease ( $\mathrm{R} 2$ resection). The role and indications for EBRT are controversial as there is no good prospective data to guide decision-making. Available evidence suggests an advantage in terms of local control in patients with R2 resections $(13,14)$. RAI ablation should also be administered either before or after EBRT; the optimal sequencing is unknown although there is concern that the remnant and disease may be less RAI avid post EBRT. Initial TSH suppression is recommended at less than $0.1 \mu \mathrm{U} / \mathrm{L}$, and then adjusted according to response to therapy (5). The response to initial therapy is prognostic; patients who have residual structural disease have a poorer outcome than those with a biochemical incomplete response (persistent Tg but no structural disease).

\section{METASTATIC DTC}

Patients with distant metastases have a reasonable life expectancy with survival measured in years. One study of patients with lung metastases reports a median overall survival (OS) of 10.45 years and a median progression-free survival (PFS) of 3.65 years (15). Even better outcomes have been described in younger patients with low disease burden (6). Several clinical factors have been reported to confer poorer outcome including older age, high FDG avidity, aggressive tumor histology, poor RAI avidity, and initial high stage (16). The most frequent sites of distant metastases are lung, bone, brain, liver and skin (6), and multiorgan metastases are associated with a poorer survival compared to single-organ metastases (17). Treatment for metastatic disease includes TSH suppression $(\mathrm{TSH}<0.1 \mu \mathrm{U} / \mathrm{L})$ and RAI therapy while the disease remains iodine avid and sensitive. RAI is the first line and a very effective treatment for distant metastases from papillary and follicular carcinoma (18). Two-thirds of patients with distant metastases will have disease that is RAI avid. Treatments every 6-12 months depending on rate of growth and response can be considered. About one-third of patients will achieve remission (i.e., negative imaging), after a median cumulative 131-I activity of $8.1 \mathrm{GBq}(220 \mathrm{mCi})$ (6). There is no specific upper limit of RAI treatment but once the disease stops taking up RAI, progresses in spite of RAI or new non-avid disease appears, then there is no benefit with further treatments and alternative therapies should be considered. Despite seventy years of medical use of RAI, there are still controversies on the optimal therapeutic activity (19). There are two main approaches to RAI therapy: an empiric (administration of standard activities) or a dosimetry-based (prescribing to predicted absorbed radiation dose) approach. OS between the two different approaches has been evaluated although only in a retrospective review comparing patients treated by an empiric fixed activity of $3.7 \mathrm{GBq}$ in one center with those treated by personalized activity $(2.7-18.6 \mathrm{GBq})$ based on whole-body/blood clearance (WB/BC) dosimetry in another. There was no OS advantage for the dosimetric approach; however, there were inherent problems with such a retrospective review (20) and clearly prospective randomized data is required to fully answer this question. Locally ablative treatments such as surgery, radiofrequency ablation (RFA), cryoablation, EBRT, chemo-embolization, and ethanol ablation can be used in selected patients for specific areas of problematic disease. Most of the available data regarding focused locally ablative therapy have been obtained from non-thyroid cancer patients and the standard of care can vary significantly between different cancer centers. In selected patients, local treatment modalities such as stereotactic radiation therapy (SBRT) and percutaneous ablation may be as effective as surgery to induce local tumor control and could represent a first-line treatment. These modalities can be useful in improving symptom control and delaying the initiation of systemic treatment or during systemic therapy where targeting progression in a single lesion may enable continued overall control of disease (5). RFA or SBRT may afford for local control in solitary lung metastases. RFA is a well-tolerated treatment that showed high efficacy in clinical trials of lung metastases from other solid tumors, with a complete response in $88-93 \%$ of patients with after $12-18$ months and local control rates ranging from 63 to $98 \%(21-23)$. There are no data on the efficacy in thyroid cancer specifically. The most common site of bone metastases is the spine, frequently associated with neurological deficit, reduced quality of life due to pain, and increased mortality (24). Treatment options include surgical resection, vertebroplasty, EBRT (including SBRT), and RFA. These local treatments are indicated for symptomatic or imminently symptomatic disease, even in the presence of RAI uptake (25). Seventy percent of patients with metastatic DTC involving bones developed at least one skeletal-related event: spinal cord compression, pathological fracture, requiring EBRT or surgery or malignant hypercalcemia (26). Bisphosphonate or denosumab therapy should be considered in patients with symptomatic and/or diffuse bone metastases. These agents delay time to occurrence of events and improve symptoms (27). Three-monthly versus monthly intravenous infusion of bisphosphonates is still a matter of debate and randomized trial data are needed. Brain metastases usually occur in older patients and are associated with poor prognosis. Neurosurgical resection, SBRT, or whole brain radiotherapy are the main treatments $(28,29)$. Whole brain RT should be considered with multiple widely spread metastases but SBRT can be used for a low number of small volume deposits in patients with a good performance status. RAI therapy may be effective, with concomitant glucocorticoid therapy prior to treatment to minimize edema and subsequent neurological deterioration. RFA represents a useful treatment modality in patients with liver metastases replacing techniques such as cryoablation, due to better efficacy, lower complication rate, and lower incidence of tumor recurrence (30). In highly vascularized tumors, RFA may be preceded by selective transarterial embolization, because the decrease in 
blood supply reduces local heat dissipation and allows tumor necrosis (31). RFA of hepatic metastases achieves local control rates ranging from 40 to $80 \%(32,33)$. The morbidity rate of RFA for hepatic lesions (both primary tumors and metastases) is reported to be $4-9 \%$, with a mortality rate below $1 \%(34,35)$. SBRT has also been reported to produce local control rates ranging from 57 to $100 \%$ in liver metastases (23).

\section{RAI REFRACTORY DTC}

Limited treatment options are available for patients with progressive and RR-DTC. Conventional chemotherapy has limited efficacy and significant toxicities. Doxorubicin remains the most effective conventional agent, $60-75 \mathrm{mg} / \mathrm{m}^{2}$ every 3-4 weeks, but has poor response rates (36). A greater understanding of the biology of thyroid cancer has led to the development of "targeted" therapies. Multiple pathways are involved in tumor angiogenesis, growth, and progression. Alongside, this understanding of the molecular background to the evolution of thyroid cancer, agents have been developed to block these inappropriately activated pathways within the cancer cells. Two agents, Sorafenib and Lenvatinib, have been approved by the US Food and Drug Administration and European Medicines Agency, based on data from multi-center, randomized, double-blind, placebo-controlled phase III studies, the DECISION and SELECT trials, respectively, showing a benefit in terms of PFS over placebo.
Sorafenib is a multi-tyrosine kinase inhibitor (MKI), which shows inhibitory activity against the vascular endothelial growth factor receptors (VEGFR) 1,2, and 3, platelet-derived growth factor receptor (PDGFR) $\beta$, Raf-1, RET, and BRAF (37). In the phase III study, the median PFS in patients treated with Sorafenib was significantly improved compared to the placebo group (10.8 versus 5.8 months). Lenvatinib is a MKI of the VEGFRs 1,2 , and 3, FGFRs 1 to 4, PDGFR $\alpha$, RET, and KIT signaling networks, which significantly improved median PFS compared to placebo in the phase III study (18.3 versus 3.6 months) (38). MKIs should be started in patients with progression of measurable lesions, as defined radiologically by RECIST criteria, over the previous 12-14 months and must take into consideration tumor burden, site of the lesions, symptoms, and the risk of local complications $(7,39)$. The optimal time to start therapy with an MKI is still a matter of debate, especially for asymptomatic patients. An international, prospective, open-label, multicentre, noninterventional study (RIFTOS MKI study) is investigating the time to symptomatic progression from study entry in asymptomatic patients with progressive RR-DTC, with 700 patients estimated to be enrolled in over 20 countries (Clinical trial: 02303444) (40). Sabra et al. reported that average tumor volume doubling time of lung metastases could be used to predict eligibility for systemic therapy with MKIs, but this has to be confirmed with further data (41). Although these drugs represent a promising option for the treatment of RR-DTC, they are associated with significant side effects

TABLE 1 | Most common toxicities for the two licensed multi-tyrosine kinase inhibitors reported in clinical trials (more than 5\%).

\begin{tabular}{|c|c|c|c|c|c|}
\hline \multicolumn{3}{|c|}{ Sorafenib $(N=207)$} & \multicolumn{3}{|c|}{ Lenvatinib $(N=261)$} \\
\hline & All grades (\%) & Grade $\geq 3(\%)$ & & All grades (\%) & Grade $\geq 3(\%)$ \\
\hline Hand-foot skin reaction & 76.3 & 20.3 & Hypertension & 67.8 & 41.8 \\
\hline Diarrhea & 68.6 & 5.3 & Serum thyroid-stimulating hormone $(\mathrm{TSH})$ increase $^{a}$ & 61.5 & - \\
\hline Alopecia & 67.1 & - & Diarrhea & 59.4 & 8 \\
\hline Rash/desquamation & 50.2 & 4.8 & Fatigue & 59.0 & 9.2 \\
\hline Fatigue & 49.8 & 5.8 & Anorexia & 50.2 & 5.4 \\
\hline Weight loss & 46.9 & 5.8 & Weight loss & 46.4 & 9.6 \\
\hline Hypertension & 40.6 & 9.7 & Nausea & 41.0 & 2.3 \\
\hline Serum TSH increase ${ }^{a}$ & 33.3 & - & Stomatitis & 35.6 & 4.2 \\
\hline Anorexia & 31.9 & 2.4 & Hand-foot skin reaction & 31.8 & 3.4 \\
\hline Oral mucositis & 23.2 & 1 & Proteinuria & 31 & 10 \\
\hline Pruritus & 21.3 & 1 & Vomiting & 28.4 & 1.9 \\
\hline Nausea & 20.8 & 0 & Headache & 27.6 & 2.7 \\
\hline Headache & 17.9 & 0 & Dysphonia & 24.1 & 1.1 \\
\hline Cough & 15.5 & 0 & Arthralgia & 18 & 0 \\
\hline Constipation & 15 & 0 & Dysgeusia & 16.9 & 0 \\
\hline Dyspnea & 14.5 & 4.8 & Rash & 16.1 & 0.4 \\
\hline Neuropathy (sensory) & 14.5 & 1 & Constipation & 14.6 & 0.4 \\
\hline Abdominal pain & 14 & 1.4 & Myalgia & 14.6 & 1.5 \\
\hline Pain (extremity) & 13.5 & 0.5 & Dry mouth & 13.8 & 0.4 \\
\hline Dermatology (other) & 13 & 1 & Upper abdominal pain & 13 & 0 \\
\hline Voice changes & 12.1 & 0.5 & Abdominal pain & 11.5 & 0.4 \\
\hline Fever & 11.1 & 1.5 & Peripheral edema & 11.1 & 0.4 \\
\hline Vomiting & 11.1 & 0.5 & Alopecia & 11.1 & 0 \\
\hline Back pain & 10.6 & 1 & Dyspepsia & 10 & 0 \\
\hline Pain (other) & 10.6 & 0.5 & Oropharyngeal pain & 10 & 0.4 \\
\hline Pain (throat, pharynx, larynx) & 10.1 & 0 & QTc prolungation & 8 & 1.5 \\
\hline Hypocalcemia & 18.8 & 9.2 & Hypocalcemia & 6.9 & 2.7 \\
\hline Increased ALT & 12.6 & 2.9 & Arterial thromboembolic effects & 5.4 & 2.7 \\
\hline Increased AST & 11.1 & 1 & & & \\
\hline
\end{tabular}

a More than $0.5 \mu / U / L$.

Adapted from Ref. $(37,38)$. 
including most commonly hypertension, diarrhea, hand/foot skin reactions, rash, fatigue, mucositis, loss of appetite, and weight loss (Table 1). An important adverse event of some kinase inhibitors can be prolongation of QT interval on electrocardiograms (ECGs), which if unchecked and unresolved lead to the risk of Torsade de Pointes and other arrhythmias. Although this AE is not commonly reported with either sorafenib or lenvatinib (it is seen with vandetanib licensed for advanced MTC), ECGs should be carried out at baseline and at each follow-up to monitor this and interruption of the drug and cardiology review should be sought. Many commonly used drugs cause QT prolongation, so, a regularly updated review of a patient's concomitant medications must be part of the assessment. The impact of these adverse events (AEs) on quality of life versus any potential benefit for the patient must be carefully evaluated. Most AEs will occur within the first few weeks of treatment. It is, therefore, recommended that patients are reviewed every 7-15 days for the first month in order to detect toxicities early and intervene with supportive medication, e.g., antihypertensives, antidiarrhoeals, and advice such as skin care. If these methods are not successful, drug dose reduction or interruption may be required $(42,43)$. Subsequently, monthly visits and then less frequently once a tolerable and effective dose is established. Monitoring of affective disorders is also important and these drugs can lower mood and at worst lead to suicidal ideation. Prompt management of AEs is fundamental to maintaining dose intensity and quality of life on these drugs (44). An area of active research is the attempt to reverse the refractoriness for RAI by trying to re-establish uptake by thyroid cancer cells. A single-center small trial has tested a MEK inhibitor, Selumetinib, in patients with RR-DTC, with promising results in a subgroup of patients. An increase in uptake on iodine-124 PET/CT in 12 out of 20 patients reaching an arbitrary dosimetry threshold for RAI therapy in 8 patients (45). While these results are promising, questions remain unanswered and currently the SEL-I-METRY trial (EudraCT no. 2015-002269-47) in United Kingdom is trying build on this preliminary data in RR-DTC (46).

\section{CURRENT ISSUES IN ADVANCED THYROID CANCER}

The 2015 ATA guidelines encourage a less aggressive approach toward DTC, for example, supporting lobectomy instead of total thyroidectomy for low-risk DTC, reducing thyroid hormone suppression based upon risk of disease recurrence and revaluating the impact of microscopic ETE $(5,47)$. Active surveillance has been proposed for papillary micro-carcinoma, after initial studies from Japan that have shown that immediate surgery and watchful waiting are equally effective in avoiding deaths from thyroid cancer (48). In an observational study of 291 patients in the United States, DTC $\leq 1.5 \mathrm{~cm}$ were actively observed and growth in tumor diameter of $3 \mathrm{~mm}$ or more was found in only $3.8 \%$ of patients, suggesting that this approach might be reasonable (49).

The impact of a less aggressive approach on A-DTC is not known. The dramatic increase in the incidence of DTC is probably due to increased medical surveillance and most of these DTC were small, low-risk papillary carcinomas where a large fraction could represent over-diagnosis, with unnecessary surgery and potential other harmful cancer treatments (50). However, the SEER data also show an increase of thyroid cancer mortality of $1.1 \%$ per year from 1994 to 2013 overall and $2.9 \%$ for metastatic DTC (51). Despite the paradigm shift toward reduced intensity treatment for DTC, A-DTC may cause significant symptoms and shortening of life and should be managed proactively. The search to find predictive and prognostic biomarkers to identify which patients will develop A-DTC continues.

\section{FUTURE PERSPECTIVES}

Significant progress has been made in the management of A-DTC. The approval of two drugs, Sorafenib and Lenvatinib, following phase 3 data showing delayed time to disease progression compared to placebo means there are now treatment options for RR-DTC. Identification of patients who will not respond to initial treatment and go on to develop A-DTC remains an area of active research. Our understanding of the molecular basis of papillary thyroid carcinoma (PTC) has been greatly enhanced following an extensive genomic analysis completed as part of the cancer genome atlas. This led to the identification of the driver genetic alterations in more than $90 \%$ of PTC, with broad implications for diagnosis, prognosis, and therapeutic targets. Indeed, molecular signatures are expected to have a significant impact on therapeutic decisions in all forms of DTC, PDTC, and ATC, perhaps guiding clinicians as to which groups of patients warrant treatment, which treatment is likely to be the most effective, thereby providing a truly personalized approach. With this targeted approach, promising results have been obtained in BRAF-mutated PTC with the selective BRAF inhibitors dabrafenib and vemurafenib $(52,53)$. Treatments directed at the VEGFR including axitinib, pazopanib, motesanib, and sunitinib have also shown activity in A-DTC (54-57). Finally, immunotherapy is being explored in A-DTC. Pembrolizumab, a checkpoint inhibitor against the programmed death protein-1, is currently being tested in combination with lenvatinib or as second line after progression on lenvatinib (https://ClinicalTrials.gov Identifier: NCT02973997).

\section{CONCLUSION}

In the past decade, advances in the treatment of DTC have been achieved. Surgery, TSH suppression and RAI remain the most effective modalities for patients at higher risk for disease recurrence or mortality. Advances in assessment and management of A-DTC have led to excellent survival outcomes. Targeted therapies, specifically MKIs, are changing the therapeutic landscape for patients with RR-DTC. Active areas of research include the definition of the optimal time of initiation systemic therapy, molecular characterization to refine treatment decisions and the possible efficacy of immunotherapy.

\section{AUTHOR CONTRIBUTIONS}

DT, FF, and KN have made a substantial, direct, and intellectual contribution to the work and approved it for publication. 


\section{REFERENCES}

1. Cabanillas ME, McFadden DG, Durante C. Thyroid cancer. Lancet (2016) 388(10061):2783-95. doi:10.1016/S0140-6736(16)30172-6

2. Segal K, Shpitzer T, Hazan A, Bachar G, Marshak G, Popovtzer A. Invasive well-differentiated thyroid carcinoma: effect of treatment modalities on outcome. Otolaryngol Head Neck Surg (2006) 134(5):819-22. doi:10.1016/j. otohns.2005.11.040

3. Wang LY, Nixon IJ, Patel SG, Palmer FL, Tuttle RM, Shaha A, et al. Operative management of locally advanced, differentiated thyroid cancer. Surgery (2016) 160(3):738-46. doi:10.1016/j.surg.2016.04.027

4. Ruegemer JJ, Hay ID, Bergstralh EJ, Ryan JJ, Offord KP, Gorman CA. Distant metastases in differentiated thyroid carcinoma: a multivariate analysis of prognostic variables. J Clin Endocrinol Metab (1988) 67(3):501-8. doi:10.1210/ jcem-67-3-501

5. Haugen BR, Alexander EK, Bible KC, Doherty GM, Mandel SJ, Nikiforov YE, et al. 2015 American Thyroid Association Management Guidelines for adult patients with thyroid nodules and differentiated thyroid cancer: the American Thyroid Association Guidelines Task Force on thyroid nodules and differentiated thyroid cancer. Thyroid (2016) 26(1):1-133. doi:10.1089/ thy.2015.0020

6. Durante C, Haddy N, Baudin E, Leboulleux S, Hartl D, Travagli JP, et al. Long-term outcome of 444 patients with distant metastases from papillary and follicular thyroid carcinoma: benefits and limits of radioiodine therapy. J Clin Endocrinol Metab (2006) 91(8):2892-9. doi:10.1210/jc.2005-2838

7. Schlumberger M, Brose M, Elisei R, Leboulleux S, Luster M, Pitoia F, et al. Definition and management of radioactive iodine-refractory differentiated thyroid cancer. Lancet Diabetes Endocrinol (2014) 2(5):356-8. doi:10.1016/ S2213-8587(13)70215-8

8. Asioli S, Erickson LA, Righi A, Jin L, Volante M, Jenkins S, et al. Poorly differentiated carcinoma of the thyroid: validation of the Turin proposal and analysis of IMP3 expression. Mod Pathol (2010) 23(9):1269-78. doi:10.1038/ modpathol.2010.117

9. Andersen PE, Kinsella J, Loree TR, Shaha AR, Shah JP. Differentiated carcinoma of the thyroid with extrathyroidal extension. Am J Surg (1995) 170(5):467-70. doi:10.1016/S0002-9610(99)80331-6

10. Amin MB, Greene FL, Edge SB, Compton CC, Gershenwald JE, Brookland RK, et al. The Eighth Edition AJCC Cancer Staging Manual: continuing to build a bridge from a population-based to a more "personalized" approach to cancer staging. CA Cancer J Clin (2017) 67(2):93-9. doi:10.3322/caac.21388

11. Nixon IJ, Simo R, Newbold K, Rinaldo A, Suarez C, Kowalski LP, et al. Management of invasive differentiated thyroid cancer. Thyroid (2016) 26(9):1156-66. doi:10.1089/thy.2016.0064

12. Varvares MA, Walker RJ. Letter to the editor regarding: management of invasive well-differentiated thyroid cancer: an American Head and Neck Society Consensus Statement. Head Neck (2016) 38(2):328-9. doi:10.1002/ hed. 24288

13. Chow SM, Yau S, Kwan CK, Poon PC, Law SC. Local and regional control in patients with papillary thyroid carcinoma: specific indications of external radiotherapy and radioactive iodine according to $\mathrm{T}$ and $\mathrm{N}$ categories in AJCC 6th edition. Endocr Relat Cancer (2006) 13(4):1159-72. doi:10.1677/ erc. 1.01320

14. Schwartz DL, Lobo MJ, Ang KK, Morrison WH, Rosenthal DI, Ahamad A, et al. Postoperative external beam radiotherapy for differentiated thyroid cancer: outcomes and morbidity with conformal treatment. Int J Radiat Oncol Biol Phys (2009) 74(4):1083-91. doi:10.1016/j.ijrobp.2008.09.023

15. Sabra MM, Ghossein R, Tuttle RM. Time course and predictors of structural disease progression in pulmonary metastases arising from follicular cell-derived thyroid cancer. Thyroid (2016) 26(4):518-24. doi:10.1089/thy.2015.0395

16. Robbins RJ, Wan Q, Grewal RK, Reibke R, Gonen M, Strauss HW, et al. Real-time prognosis for metastatic thyroid carcinoma based on 2-[18F] fluoro-2-deoxy-D-glucose-positron emission tomography scanning. J Clin Endocrinol Metab (2006) 91(2):498-505. doi:10.1210/jc.2005-1534

17. Wang LY, Palmer FL, Nixon IJ, Thomas D, Patel SG, Shaha AR, et al. Multiorgan distant metastases confer worse disease-specific survival in differentiated thyroid cancer. Thyroid (2014) 24(11):1594-9. doi:10.1089/thy.2014.0173

18. Maxon HR III, Smith HS. Radioiodine-131 in the diagnosis and treatment of metastatic well differentiated thyroid cancer. Endocrinol Metab Clin North Am (1990) 19(3):685-718.
19. Blumhardt R, Wolin EA, Phillips WT, Salman UA, Walker RC, Stack BC Jr., et al. Current controversies in the initial post-surgical radioactive iodine therapy for thyroid cancer: a narrative review. Endocr Relat Cancer (2014) 21(6):R473-84. doi:10.1530/ERC-14-0286

20. Deandreis D, Rubino C, Tala H, Leboulleux S, Terroir M, Baudin E, et al. Comparison of empiric versus whole-body/-blood clearance dosimetry-based approach to radioactive iodine treatment in patients with metastases from differentiated thyroid cancer. J Nucl Med (2017) 58(5):717-22. doi:10.2967/ jnumed.116.179606

21. Lencioni R, Crocetti L, Cioni R, Suh R, Glenn D, Regge D, et al. Response to radiofrequency ablation of pulmonary tumours: a prospective, intention-totreat, multicentre clinical trial (the RAPTURE study). Lancet Oncol (2008) 9(7):621-8. doi:10.1016/S1470-2045(08)70155-4

22. de Baere T, Palussiere J, Auperin A, Hakime A, Abdel-Rehim M, Kind M, et al. Midterm local efficacy and survival after radiofrequency ablation of lung tumors with minimum follow-up of 1 year: prospective evaluation. Radiology (2006) 240(2):587-96. doi:10.1148/radiol.2402050807

23. Lo SS, Fakiris AJ, Chang EL, Mayr NA, Wang JZ, Papiez L, et al. Stereotactic body radiation therapy: a novel treatment modality. Nat Rev Clin Oncol (2010) 7(1):44-54. doi:10.1038/nrclinonc.2009.188

24. Kushchayeva YS, Kushchayev SV, Wexler JA, Carroll NM, Preul MC, Teytelboym OM, et al. Current treatment modalities for spinal metastases secondary to thyroid carcinoma. Thyroid (2014) 24(10):1443-55. doi:10.1089/ thy. 2013.0633

25. Schlumberger M, Leboulleux S. Treatment of distant metastases from follicular cell-derived thyroid cancer. F1000Prime Rep (2015) 7:22. doi:10.12703/P7-22

26. Farooki A, Leung V, Tala H, Tuttle RM. Skeletal-related events due to bone metastases from differentiated thyroid cancer. J Clin Endocrinol Metab (2012) 97(7):2433-9. doi:10.1210/jc.2012-1169

27. Coleman R, Gnant M, Morgan G, Clezardin P. Effects of bone-targeted agents on cancer progression and mortality. J Natl Cancer Inst (2012) 104(14): 1059-67. doi:10.1093/jnci/djs263

28. Henriques de Figueiredo B, Godbert Y, Soubeyran I, Carrat X, Lagarde P, Cazeau AL, et al. Brain metastases from thyroid carcinoma: a retrospective study of 21 patients. Thyroid (2014) 24(2):270-6. doi:10.1089/thy.2013.0061

29. McWilliams RR, Giannini C, Hay ID, Atkinson JL, Stafford SL, Buckner JC. Management of brain metastases from thyroid carcinoma: a study of 16 pathologically confirmed cases over 25 years. Cancer (2003) 98(2):356-62. doi:10.1002/cncr.11488

30. de Jong KP. Freeze or fry - cryoablation or radiofrequency ablation in liver surgery? Nat Clin Pract Gastroenterol Hepatol (2007) 4(9):472-3. doi:10.1038/ ncpgasthep0905

31. Wertenbroek MW, Links TP, Prins TR, Plukker JT, van der Jagt EJ, de Jong KP. Radiofrequency ablation of hepatic metastases from thyroid carcinoma. Thyroid (2008) 18(10):1105-10. doi:10.1089/thy.2008.0080

32. de Baere T, Elias D, Dromain C, Din MG, Kuoch V, Ducreux M, et al. Radiofrequency ablation of 100 hepatic metastases with a mean follow-up of more than 1 year. AJR Am J Roentgenol (2000) 175(6):1619-25. doi:10.2214/ ajr.175.6.1751619

33. Solbiati L, Livraghi T, Goldberg SN, Ierace T, Meloni F, Dellanoce M, et al. Percutaneous radio-frequency ablation of hepatic metastases from colorectal cancer: long-term results in 117 patients. Radiology (2001) 221(1):159-66. doi:10.1148/radiol.2211001624

34. Berber E, Siperstein AE. Perioperative outcome after laparoscopic radiofrequency ablation of liver tumors: an analysis of 521 cases. Surg Endosc (2007) 21(4):613-8. doi:10.1007/s00464-006-9139-y

35. Curley SA, Marra P, Beaty K, Ellis LM, Vauthey JN, Abdalla EK, et al. Early and late complications after radiofrequency ablation of malignant liver tumors in 608 patients. Ann Surg (2004) 239(4):450-8. doi:10.1097/01.sla.0000118373.31781.f2

36. Sherman SI. Cytotoxic chemotherapy for differentiated thyroid carcinoma. Clin Oncol (R Coll Radiol) (2010) 22(6):464-8. doi:10.1016/j.clon.2010. 03.014

37. Brose MS, Nutting CM, Jarzab B, Elisei R, Siena S, Bastholt L, et al. Sorafenib in radioactive iodine-refractory, locally advanced or metastatic differentiated thyroid cancer: a randomised, double-blind, phase 3 trial. Lancet (2014) 384(9940):319-28. doi:10.1016/S0140-6736(14)60421-9

38. Schlumberger M, Tahara M, Wirth LJ, Robinson B, Brose MS, Elisei R, et al. Lenvatinib versus placebo in radioiodine-refractory thyroid cancer. $N$ Engl J Med (2015) 372(7):621-30. doi:10.1056/NEJMoa1406470 
39. Eisenhauer EA, Therasse P, Bogaerts J, Schwartz LH, Sargent D, Ford R, et al. New response evaluation criteria in solid tumours: revised RECIST guideline (version 1.1). Eur J Cancer (2009) 45(2):228-47. doi:10.1016/j.ejca.2008.10.026

40. Brose MS, Smit JW, Lin CC, Pitoia F, Fellous M, DeSanctis Y, et al. Timing of multikinase inhibitor initiation in differentiated thyroid cancer. Endocr Relat Cancer (2017) 24(5):237-42. doi:10.1530/ERC-17-0016

41. Sabra MM, Sherman EJ, Tuttle RM. Tumor volume doubling time of pulmonary metastases predicts overall survival and can guide the initiation of multikinase inhibitor therapy in patients with metastatic, follicular cell-derived thyroid carcinoma. Cancer (2017) 123(15):2955-64. doi:10.1002/cncr.30690

42. Haddad RI, Schlumberger M, Wirth LJ, Sherman EJ, Shah MH, Robinson B, et al. Incidence and timing of common adverse events in lenvatinib-treated patients from the SELECT trial and their association with survival outcomes. Endocrine (2017) 56(1):121-8. doi:10.1007/s12020-017-1233-5

43. Ahmed M, Barbachano Y, Riddell A, Hickey J, Newbold KL, Viros A, et al. Analysis of the efficacy and toxicity of sorafenib in thyroid cancer: a phase II study in a UK based population. Eur J Endocrinol (2011) 165(2):315-22. doi:10.1530/EJE-11-0129

44. Grande E, Kreissl MC, Filetti S, Newbold K, Reinisch W, Robert C, et al. Vandetanib in advanced medullary thyroid cancer: review of adverse event management strategies. Adv Ther (2013) 30(11):945-66. doi:10.1007/ s12325-013-0069-5

45. Ho AL, Grewal RK, Leboeuf R, Sherman EJ, Pfister DG, Deandreis D, et al. Selumetinib-enhanced radioiodine uptake in advanced thyroid cancer. N Engl J Med (2013) 368(7):623-32. doi:10.1056/NEJMoa1209288

46. Newbold KL, Flux G, Wadsley J. Radioiodine for high risk and radioiodine refractory thyroid cancer: current concepts in management. Clin Oncol (R Coll Radiol) (2017) 29(5):307-9. doi:10.1016/j.clon.2016.12.008

47. Tavarelli M, Sarfati J, Chereau N, Tissier F, Golmard JL, Ghander C, et al. Heterogeneous prognoses for pT3 papillary thyroid carcinomas and impact of delayed risk stratification. Thyroid (2017) 27(6):778-86. doi:10.1089/ thy.2016.0512

48. Ito Y, Miyauchi A, Kihara M, Higashiyama T, Kobayashi K, Miya A. Patient age is significantly related to the progression of papillary microcarcinoma of the thyroid under observation. Thyroid (2014) 24(1):27-34. doi:10.1089/ thy.2013.0367

49. Tuttle RM, Fagin JA, Minkowitz G, Wong RJ, Roman B, Patel S, et al. Natural history and tumor volume kinetics of papillary thyroid cancers during active surveillance. JAMA Otolaryngol Head Neck Surg (2017) 143(10):1015-20. doi:10.1001/jamaoto.2017.1442
50. Vaccarella S, Franceschi S, Bray F, Wild CP, Plummer M, Dal Maso L. Worldwide thyroid-cancer epidemic? The increasing impact of overdiagnosis. N Engl J Med (2016) 375(7):614-7. doi:10.1056/NEJMp1604412

51. Lim H, Devesa SS, Sosa JA, Check D, Kitahara CM. Trends in thyroid cancer incidence and mortality in the United States, 1974-2013. JAMA (2017) 317(13):1338-48. doi:10.1001/jama.2017.2719

52. Falchook GS, Millward M, Hong D, Naing A, Piha-Paul S, Waguespack SG, et al. BRAF inhibitor dabrafenib in patients with metastatic BRAF-mutant thyroid cancer. Thyroid (2015) 25(1):71-7. doi:10.1089/thy.2014.0123

53. Hyman DM, Puzanov I, Subbiah V, Faris JE, Chau I, Blay JY, et al. Vemurafenib in multiple nonmelanoma cancers with BRAF V600 mutations. $N$ Engl J Med (2015) 373(8):726-36. doi:10.1056/NEJMoa1502309

54. Locati LD, Licitra L, Agate L, Ou SH, Boucher A, Jarzab B, et al. Treatment of advanced thyroid cancer with axitinib: phase 2 study with pharmacokinetic/pharmacodynamic and quality-of-life assessments. Cancer (2014) 120(17):2694-703. doi:10.1002/cncr.28766

55. Bible KC, Suman VJ, Molina JR, Smallridge RC, Maples WJ, Menefee ME, et al. Efficacy of pazopanib in progressive, radioiodine-refractory, metastatic differentiated thyroid cancers: results of a phase 2 consortium study. Lancet Oncol (2010) 11(10):962-72. doi:10.1016/S1470-2045(10)70203-5

56. Sherman SI, Wirth LJ, Droz JP, Hofmann M, Bastholt L, Martins RG, et al. Motesanib diphosphate in progressive differentiated thyroid cancer. $N$ Engl J Med (2008) 359(1):31-42. doi:10.1056/NEJMoa075853

57. Carr LL, Mankoff DA, Goulart BH, Eaton KD, Capell PT, Kell EM, et al. Phase II study of daily sunitinib in FDG-PET-positive, iodine-refractory differentiated thyroid cancer and metastatic medullary carcinoma of the thyroid with functional imaging correlation. Clin Cancer Res (2010) 16(21):5260-8. doi:10.1158/1078-0432.CCR-10-0994

Conflict of Interest Statement: KN has had advisory and speakers' bureau roles with Astra-Zeneca, Eisai, and Sanofi-Genzyme. All other authors declare that the research was conducted in the absence of any commercial or financial relationships that could be construed as a potential conflict of interest.

Copyright (C) 2017 Tumino, Frasca and Newbold. This is an open-access article distributed under the terms of the Creative Commons Attribution License (CC BY). The use, distribution or reproduction in other forums is permitted, provided the original author(s) or licensor are credited and that the original publication in this journal is cited, in accordance with accepted academic practice. No use, distribution or reproduction is permitted which does not comply with these terms. 